\title{
Poor working memory predicts false memories
}

Citation for published version (APA):

Peters, M. J. V., Jelicic, M., Verbeek, H., \& Merckelbach, H. L. G. J. (2007). Poor working memory predicts false memories. European Journal of Cognitive Psychology, 19(2), 213-232.

https://doi.org/10.1080/09541440600760396

Document status and date:

Published: 01/01/2007

DOI:

10.1080/09541440600760396

Document Version:

Publisher's PDF, also known as Version of record

\section{Please check the document version of this publication:}

- A submitted manuscript is the version of the article upon submission and before peer-review. There can be important differences between the submitted version and the official published version of record.

People interested in the research are advised to contact the author for the final version of the publication, or visit the DOI to the publisher's website.

- The final author version and the galley proof are versions of the publication after peer review.

- The final published version features the final layout of the paper including the volume, issue and page numbers.

Link to publication

\footnotetext{
General rights rights.

- You may freely distribute the URL identifying the publication in the public portal. please follow below link for the End User Agreement:

www.umlib.nl/taverne-license

Take down policy

If you believe that this document breaches copyright please contact us at:

repository@maastrichtuniversity.nl

providing details and we will investigate your claim.
}

Copyright and moral rights for the publications made accessible in the public portal are retained by the authors and/or other copyright owners and it is a condition of accessing publications that users recognise and abide by the legal requirements associated with these

- Users may download and print one copy of any publication from the public portal for the purpose of private study or research.

- You may not further distribute the material or use it for any profit-making activity or commercial gain

If the publication is distributed under the terms of Article $25 \mathrm{fa}$ of the Dutch Copyright Act, indicated by the "Taverne" license above, 
This article was downloaded by:[Peters, Maarten]

On: 24 J anuary 2007

Access Details: [subscription number 770216929]

Publisher: Psychology Press

Informa Ltd Registered in England and Wales Registered Number: 1072954

Registered office: Mortimer House, 37-41 Mortimer Street, London W1T 3J H, UK

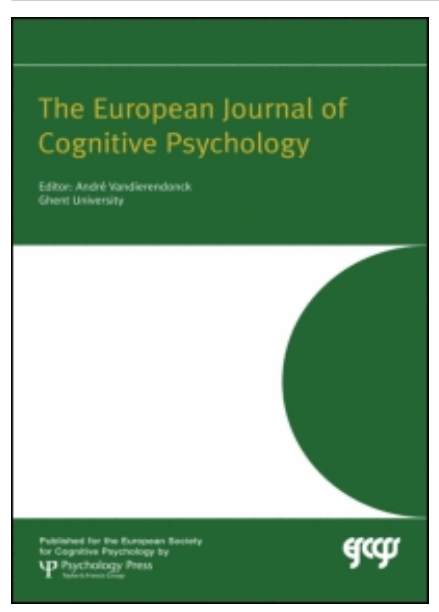

\section{E uropean J ournal of Cognitive} P sychology

Publication details, including instructions for authors and subscription information: http://www.informaworld.com/smpp/title $\sim$ content=t713734596 Poor working memory predicts false memories

First Published on: 05 J uly 2006

To link to this article: DOI: $10.1080 / 09541440600760396$

URL: http://dx.doi.org/10.1080/09541440600760396

Full terms and conditions of use: $h$ ttp://www.informaworld.com/terms-and-conditions-of-access.pdf This article maybe used for research, teaching and private study purposes. Any substantial or systematic reproduction, re-distribution, re-selling, loan or sub-licensing, systematic supply or distribution in any form to anyone is expressly forbidden.

The publisher does not give any warranty express or implied or make any representation that the contents will be complete or accurate or up to date. The accuracy of any instructions, formulae and drug doses should be independently verified with primary sources. The publisher shall not be liable for any loss, actions, claims, proceedings, demand or costs or damages whatsoever or howsoever caused arising directly or indirectly in connection with or arising out of the use of this material.

(c) Taylor and Francis 2007 


\title{
Poor working memory predicts false memories
}

\author{
Maarten J.V. Peters, Marko Jelicic, Hilde Verbeek, and \\ Harald Merckelbach \\ Department of Experimental Psychology, Faculty of Psychology, Maastricht \\ University, Maastricht, The Netherlands
}

\begin{abstract}
Two studies investigated whether individual differences in simple span verbal working memory and complex working memory capacity are related to memory accuracy and susceptibility to false memory development. In Study 1, undergraduate students $(N=60)$ were given two simple span working memory tests: forward and backward digit span. They also underwent a memory task that is known to elicit false memories of nonpresented words, the Deese/RoedigerMcDermott (DRM) paradigm. Poor simple span working memory (as reflected by suboptimal backward digit span scores) was related to elevated levels of false recognition. Study $2(N=65)$ replicated this finding, in that suboptimal backward digit span performance was found to be predictive of false recognition. However, complex working memory capacity (operation span) was not related to false recognition. This pattern suggests that even in a homogenous sample of undergraduates, poor working memory is associated with the susceptibility to recollect words never presented.
\end{abstract}

During memory retrieval, various encoded pieces of the memory trace need to be integrated into a reconstructive recollection of an event. This memory binding process has been the object of much research and has been ascribed to a neural network encompassing posterior brain regions, the hippocampus, and the prefrontal cortex (e.g., Kroll, Knight, Metcalfe, Wolf, \& Tulving, 1996; Moscovitch, 2000). Apart from their role in accurate retrieval, various researchers have argued that cognitive functions related to this neural network (working memory, monitoring, executive control) are also involved

Correspondence should be addressed to Maarten J. V. Peters, Department of Experimental Psychology, Faculty of Psychology, Maastricht University, PO Box 616, 6200 MD, Maastricht, The Netherlands. E-mail: m.peters@psychology.unimaas.nl

This study was supported by a grant from the Dutch organisation for scientific research NWO grant number 452-02-006. We would like to thank Dr. Jason Watson, associate editor Professor Nelson Cowan, and two anonymous reviewers for their constructive comments on an earlier version of the manuscript, and Kevin Sijstermans and Benny Gorski for their help in recruiting and testing participants.

(C) 2006 Psychology Press, an imprint of the Taylor and Francis Group, an informa business http://www.psypress.com/ecp

DOI: $10.1080 / 09541440600760396$ 
in the creation of distortions (e.g., remembering a blue car, when the colour of the car was red) and false memories (remembering events that never took place; e.g., Dodson \& Schacter, 2002; Gonsalves \& Paller, 2002; Kopelman 1999, 2002; Marsch, Balota, \& Roediger, 2005; Melo, Winocur, \& Moscovitch, 1999; Parkin, 1997; Schacter, 1999; Schacter \& Slotnick, 2004). One important antecedent of false memories is a breakdown in what has been termed source monitoring (Johnson, Hashtroudi, \& Lindsay, 1993). Source monitoring refers to the mechanism that allows people to determine the source of memory information. It is a mechanism that serves as a screening and controlling device for memory at retrieval, in which distinctive perceptual information plays an important role in labelling events as veridical.

The crux of working memory is the maintenance and manipulation of information, both during memory storage and retrieval from long-term store (e.g., Baddeley \& Hitch, 1974; D’Esposito \& Postle, 2002; Kane \& Engle, 2002). Working memory is closely connected to executive functioning and the prefrontal cortex (e.g., D'Esposito \& Postle, 2002). There are also good reasons to believe that working memory subserves source monitoring (e.g., Hedden \& Park, 2003; Mitchell, Johnson, Raye, \& Greene, 2004; Moscovitch, 2000; Reinitz \& Hannigan, 2004). Studies that support this line of reasoning were carried out by Mitchell and colleagues (2004) and Reinitz and Hannigan (2004). Mitchell et al. conducted a study to identify the neural correlates related to maintaining memory representations active in working memory for subsequent source memory evaluations. In three functional magnetic resonance imaging (fMRI) experiments, a memory paradigm was used in which participants saw four items presented sequentially for $1 \mathrm{~s}$ each. To create source conditions, two of the items were presented as words, two were black-and-white line object drawings (format condition), and each of these item types were presented on the left or the right side of the screen (location condition). To maximise working memory involvement, immediately after each trial (consisting of four items), participants were probed to make source and familiarity judgements (Experiment 1). It was found that this working memory paradigm yielded greater activation in the lateral PFC for source memory judgements compared to familiarity judgements. Further support for the link between working memory and source monitoring comes from a study by Reinitz and Hannigan. In one of their three experiments, the influence of indirect overload of working memory (divided attention; digit monitoring task) on subsequent false memory development for compound words was investigated. The authors found that when participants had to monitor specific digits (total number of even digits) that were simultaneously presented with compound words (e.g., toothpaste, headache), they were more prone to later falsely remember never presented compound words (e.g., toothache), thus misattributing these separate words to their wrong source. 
Thus, it can be hypothesised that through increased susceptibility to source monitoring errors, poor working memory (either tested direct by working memory tasks or indirect by using dual tasks) may lead to an increase in false memories. One important mechanism to distinguish veridical from false memory traces is the amount of perceptual detail, with veridical memory traces exhibiting more of this distinctive information (Johnson et al., 1993). This issue is further supported by recent neuroimaging and electrophysiological studies that suggest that sensory activation is greater for true compared to false recognition (see for a review, Schacter \& Slotnick, 2004). When making source monitoring judgements, these perceptual details serve as landmarks in ascribing a memory trace as trustworthy, i.e., veridical. A source monitoring problem may arise when, during encoding of specific event information, this perceptually based information supporting source monitoring at time of retrieval is poorly encoded. This can happen when working memory capacity is overloaded, either indirectly, when situational circumstances put increasing demands on working memory (i.e., remembering telephone number and simultaneously your shopping list of tonight; dual tasks) or directly when working memory resources are poor for neurobiological reasons. Put in other words, reduced, overloaded, or suboptimal working memory processing would lead to poor encoding of perceptually based information, resulting in a lower level of active maintenance of information (e.g., source information). This could undermine performance on cognitive challenging tasks that require such active maintenance. After all, encoding and retrieval of an accurate memory representation requires information about the source of the representation (Johnson et al., 1993; see the activation-monitoring framework for a comparable line of reasoning, McDermott \& Watson, 2001), in order to make memory attributions (i.e., does this memory representation originate from an event or from a dream?; Johnson et al., 1993).

Although the connection between deficits in specific cognitive functions (working memory, executive functions) and false memories has often been studied in neurological patients (e.g., Melo et al., 1999), older people (Lödvén, 2003), and children (Alexander et al., 2002; Ruffman, Rustin, Garnham, \& Parkin, 2001), it is not unreasonable to assume that even in healthy samples, there is individual variation in the efficacy of cognitive functions that might affect their susceptibility to false memories. Surprisingly, only a few studies explored individual differences in specific cognitive functions sustained by the prefrontal cortex and hippocampus that may contribute to false memory development. In an earlier study (Peters, Jelicic, Haas, \& Merckelbach, in press), we explored whether mild executive dysfunctions (closely related to working memory) in undergraduate students are linked to false recall and recognition of semantically related words. To this end, we employed the Deese/Roediger-McDermott (DRM; Deese, 1959; 
Roediger \& McDermott, 1995) paradigm. In this paradigm, people are asked to remember lists of related words, such as bed, nap, pillow, and snooze, all of which are associated with a common word, in this particular example the word sleep. The word sleep, however, is never presented in the study list and serves as a critical lure at test. Following each list presentation, participants are asked to recall the studied items. Once all lists have been presented and recalled, participants are given a recognition test comprising the studied words, unrelated lures, and critical lures. Apart from the DRM task, participants in our study were given a test designed to assess executive function - the Random Number Generation (RNG) task. In this task, participants are asked to produce long sequences of the numbers $1-10$ in a random fashion (e.g., Ginsburg \& Karpiuk, 1994, 1995). Factor analyses on RNG data have shown that there are three clusters of random indices: repetition, seriation, and cycling, which are related to lack of output inhibition, lack of inhibition of cognitive schemata, and lack of monitoring of previous output, respectively (Ginsburg \& Karpiuk, 1994; Williams, Moss, Bradshaw, \& Rinehart, 2002). In our study (Peters et al., in press), we found that participants with high seriation scores on the RNG exhibited higher false recognition rates of the DRM critical lures than those with low seriation scores. High seriation scores reflect a lack of inhibition of cognitive schemata and, thus, mild executive dysfunctions.

Another recent study by Watson, Bunting, Poole, and Conway (2005) was the first to investigate whether individual differences in complex span working memory capacity (WMC) are related to false memories for nonpresented critical lure words in the DRM paradigm. In two experiments, undergraduate participants were initially screened with the operation span task (o-span task; La Pointe \& Engle, 1990). In this task, participants are required to read aloud a math problem, followed by a to-be-remembered word, e.g., "Is $(8 / 4)+5=7$ ? SEA." After several trials of these equationword pairs, participants are prompted to recall all of the words presented during the trials in the correct order. Operation span is defined as the sum of the correct recalled words across all individual trials. Based on this screening, 50 high and 50 low o-span participants were selected from the upper and lower quartiles of the distribution of span scores. These participants were subjected to the DRM paradigm. Half of the high and low span participants received prior to encoding an explicit warning instruction about the potential of the DRM paradigm to elicit false memories and were encouraged to avoid recalling the critical lure word for each of the associative lists. The remaining half of the high and low span participants were not given any warning (Experiment 1). The results of this experiment showed that undergraduates with low WMC (low o-span) more often falsely recalled critical lure words than individuals with high WMC (high o-span), but only so when participants had received a warning about the DRM 
paradigm. In Experiment 2, the same screening procedure was used for selecting low $(N=50)$ and high $(N=50)$ WMC undergraduates. In this second experiment a repeated DRM study-test trial procedure was used, factorially crossing the warning manipulation as in Study 1 . This is a reliable procedure for reducing false memory development in young adult research populations (e.g., McDermott, 1996; Watson, McDermott, \& Balota, 2004). Indeed, both high and low WMC participants benefited from the repeated study-test trials in the sense that this setup led to an overall reduction in recall of critical words. Taken together, these findings suggest that individual differences in WMC influence encoding of distinctive information, thereby affecting later cognitive control and the ability to actively maintain task goals. In case of poor working memory capabilities, this may result in an enhanced susceptibility to false memories in young adults.

Inspired by Watson and colleagues (2005), we conducted two studies to further disentangle the relationship between source monitoring, individual differences in working memory, and false memory development in a healthy student sample. Given that (1) source monitoring is important for avoiding errors in DRM and (2) working memory plays an important role in encoding and retrieving distinctive information necessary for accurate source monitoring, one would expect increased false memories when working memory performance is poor. However, in contrast to Watson and colleagues, who only used a complex working memory capacity task, we wanted to find out if this line of reasoning also holds for different measures (i.e., aspects) of working memory (simple vs. complex working memory capacity). Therefore, Study 1 examined whether individual differences in simple span verbal working memory are linked to false memory development as measured by the DRM paradigm. The study by Watson and colleagues did not combine recall and recognition memory tasks, and therefore we decided to include both DRM parameters in Study 1. The forward and backward digit span (DB) subtasks of the Wechsler Adult Intelligence Scale (WAIS; Wechsler, 1997; for a Dutch translation, see Stinissen, Willems, Coetsier, \& Hulsman, 1970) are widely used measures of simple span verbal working memory in neuropsychological research and clinical practice (see Iverson \& Tulsky, 2003 , for normative data). Both tasks require immediate, serial recall of a list of digits that are read out loud and, typically, the length of the digit string is increased until the participant consistently fails. The two tasks tap different aspects of working memory (Baddeley, 1996), namely the central executive (backward digit span), which serves as a controlling device for the two slave systems: phonological loop (forward digit span) and visuospatial sketchpad. Of most interest in this study is the backward digit span task, because this task is believed to rely to a large extent on the central executive component of Baddeley's model (Gerton et al., 2004). If working memory (encoding of distinctive features) subserves source monitoring, we expected that even in a 
relatively homogeneous sample of undergraduates, performance on the simple span verbal working memory test (backward digit span) would be related to false recall and recognition in the DRM paradigm. We anticipated that forward digit span (nonexecutive) performance would not or to a lesser degree be associated with false memories in this paradigm.

\section{STUDY 1}

\section{Method}

\section{Participants}

The sample consisted of 60 psychology undergraduate students (43 women) at Maastricht University. They received course credits in return for participation. Mean age of the participants was 19.58 years $(S D=2.86$; range: 18-38). Exclusion criteria were psychiatric disorders, brain injury, or language difficulties.

\section{Procedure and materials}

The study was approved by the standing ethical committee of the Faculty of Psychology of Maastricht University. Participants were tested individually in a quiet laboratory room. Upon arrival, participants were asked to sign an informed consent form. Instructions, manipulations, and stimulus materials were given on paper.

Deese/Roediger-McDermott paradigm. Participants were subjected to a Dutch version of the DRM paradigm (Deese, 1959; Roediger \& McDermott, 1995). The DRM paradigm used in the current study consisted of 10 selected word lists drawn from a Dutch normative study (Peters, Jelicic, \& Merckelbach, 2006; Peters et al., in press). Each list consisted of 15 words semantically related to a nonpresented critical lure word. The lists were read aloud one after the other. The words (spoken by a female voice) were presented for $1 \mathrm{~s}$ with an interstimulus interval of $1 \mathrm{~s}$. Unlike the study by Watson and colleagues (2005), participants did not receive a warning manipulation. After each list presentation, participants were given 2 min to write down all the words they could remember. The completion of the 10 lists was followed by the digit span task (see below). Participants were then given an old-new recognition task consisting of 10 critical lures of the studied lists completely intermixed with 30 study words (the first, eighth, and tenth word of each studied list) and 20 unrelated lures taken from nonpresented lists. Only words unrelated to the words in the studied lists served as unrelated lures. For each of these 60 words, participants had to indicate whether the word was old (i.e., had appeared on one of the 10 lists) or new. 
Forward and backward digit span. Following the DRM recall task, participants were given the digit span test to assess simple verbal working memory. It was taken from the WAIS (Wechsler, 1997; for a Dutch translation, see Stinissen et al., 1970). The test consisted of two subtests: forward and backward digit span. Strings of digits were read aloud (e.g., 24 7), each string increasing in length (from two digits to eight digits). After every string, the participant was asked to repeat the string. The test consisted of 12 strings in the normal front to back order (forward) and 12 strings in the back to front order (backward). Each subtest (forward and backward) was stopped when a participant incorrectly reproduced two successive strings. The amount of correctly reproduced strings was used as a measure of simple verbal working memory.

\section{Data analysis}

Data analyses were carried out with alpha set at .05 (two-tailed). The following six DRM indices were derived: mean accurate free recall proportions, false recall of critical lure words, false recall of unrelated lures, mean proportions of correctly recognised old words, recognition of critical lure words, and recognition of unrelated lures. Because we were primarily interested in false memories, we focused on free recall and recognition of critical lure words. First, Pearson correlations were calculated between forward and backward digit span and the six DRM parameters. Multiple regression analyses (enter method) were conducted with forward and backward digit span scores as independent measures and mean proportion recall and recognition of critical lure words as dependent variables.

\section{Results and discussion}

Table 1 summarises data about the six DRM parameters. The overall probability that participants recalled the critical lure was $.47(S D=.19)$, while that for recognising the critical lure was $.87(S D=.15)$. The mean proportion score for recognising unrelated lures as old was $.03(S D=.04)$.

Forward and backward digit span performance scores were not significantly related to each other, $r=.22, p>.05$, showing that they tap more or less independent aspects of working memory. Pearson product-moment correlations were calculated between the six DRM indices and forward and backward digit span scores. No significant correlations were found between recall and recognition of the studied words on the one and the digit span task on the other hand: recall hits, $r_{\text {forward }}=.11, p=.40 ; r_{\text {backward }}=.19$, $p=.15 ;$ recognition hits, $r_{\text {forward }}=.09, p=.52 ; r_{\text {backward }}=.16, p=.21$. Neither were there significant correlations between recall/recognition of unrelated lures and the two digit span parameters: recall unrelated lures, 
TABLE 1

Mean proportion scores (including $S D$ and range) for recall of studied words, and critical lure words, and unrelated lures and mean proportion scores for recognition of studied words, critical lure words, and unrelated words. Forward and backward digit span performances are expressed as mean overall scores

\begin{tabular}{lccc}
\hline Item type & Mean & $S D$ & Range \\
\hline Recall & & & \\
$\quad$ Recall studied words & .61 & .07 & .39 \\
Recall critical lures & .47 & .19 & .80 \\
$\quad$ Recall unrelated lures* & .03 & .02 & .07 \\
Recognition & & & \\
$\quad$ Recognition studied words & .79 & .11 & .47 \\
Recognition critical lures & .87 & .15 & .60 \\
Recognition unrelated lures & .03 & .04 & .20 \\
Digit span & & & \\
$\quad$ Forward digit span & 6.10 & 1.21 & 4.00 \\
Backward digit span & 4.65 & 1.05 & 5.00 \\
\hline
\end{tabular}

*expressed as proportion of all recalled words that were unrelated lures [recall unrelated lures divided by total recall score (sum recall studied words, critical lures and unrelated lures)].

$r_{\text {forward }}=.06, p=.62 ; r_{\text {backward }}=-.07, p=.62 ;$ recognition unrelated lures, $r_{\text {forward }}=.05, p=.70 ; r_{\text {backward }}=-.05, p=.69$. However, there was a borderline significant correlation between recall of critical lures and backward digit span, $r=-.23, p=.08$, two-tailed. Similarly, proportion recognition of critical lures was significantly and negatively correlated with backward digit span, $r=-.40, p<.01 .^{1}$ Correlations between recall/recognition of the critical lure and forward digit span remained nonsignificant, $r=-.05$, $p>.05$, and $r=-.15, p>.05$, respectively.

Two multiple linear regression analyses were carried out to determine how much variance in recall and recognition of critical lures was explained by forward and backward digit span scores. The results are shown in Table 2. Both forward and backward digit span were entered in the model (enter method) to explain the variance in recall of the critical lure word. Neither forward nor backward digit span contributed significantly to the model. A second regression model to explain the variance in recognition of critical lures by entering both forward and backward digit span showed that only backward digit span contributed significantly to falsely recognising of the

\footnotetext{
${ }^{1}$ To correct for possible ceiling effects in our critical lure data, corrected critical lure false recognition (false recognition of critical lure - false recognition of unrelated lure; $M=.81$, $S D=.16$, range $=.65$ ) was calculated and related to the digit span scores. Only backward digit span score was negatively related to corrected false recognition for critical lures indicating a similar correlation as in the initial analyses, $r=-.39, p<.01$.
} 
TABLE 2

Summary of regression analyses for variables predicting false recall and false recognition of critical lure words $(N=60)$

\begin{tabular}{lcccc}
\hline Variable & $B$ & $S E B$ & $\beta$ & $t$ \\
\hline Recall & & & & \\
$\quad$ Forward digit span & 3.27 & .02 & .00 & .00 \\
Backward digit span & -.04 & .02 & -.23 & -1.70 \\
& & & & \\
Recognition & & & & -.51 \\
$\quad$ Forward digit span & -.01 & .02 & -.06 & $-3.10^{*}$ \\
$\quad$ Backward digit span & -.06 & .02 & -.39 & \\
\hline
\end{tabular}

$R^{2}=.051$ for recall; $R^{2}=.16$ for recognition.

$B=$ unstandardised regression coefficient; $S E B=$ standard error unstandardised regression coefficient; $\beta=$ standardised regression coefficient; $t=t$-value.

$* p<.01$.

critical lure word as old. In this model $16 \%$ of the variance was explained $\left(R^{2}=.16\right)$.

The main results of our study can be summarised as follows. Backward digit span was significantly and negatively related to the recognition of critical lures. That is, poor digit span backward performance was associated with heightened levels of false recognition. A similar pattern was evident for false recall of critical lures, but this effect reached only borderline significance. Thus, relative to participants with relatively high backward digit span scores, those with relatively low backward digit span scores made more critical lure intrusions, indicating a higher susceptibility to false memories (as measured by the DRM paradigm). As expected, increased critical lure intrusions are predictable from simple span verbal working memory measures. In more general terms, then, our results show that even in a healthy sample of undergraduate students, individual differences in backward simple span working memory are related to recollecting words never presented. These results seem to support the hypothesis that when working memory processing is suboptimal, this will have an effect on encoding and later retrieval of distinctive information, leading to an increase in source monitoring errors.

Given that undergraduates generally perform well on simple span verbal working memory tasks, lowered scores on the digit span tests in the present study should not be considered indicative of neuropsychological impairments. Mean scores on the digit span forward and backward tasks (see Table 1) are well in line with those reported by Iverson and Tulsky (2003). These authors found in their standardisation sample (aged 18-19) mean scores for forward and backward digit span of $6.7(S D=1.3)$ and 5.0 
$(S D=1.5)$, respectively. The proportions of critical lures elicited by the DRM paradigm in the current study (being $47 \%$ and $84 \%$ for recall and recognition, respectively) were comparable to those reported by Roediger and McDermott (1995). In their first experiment, Roediger and McDermott found that the nonpresented critical lures were recalled $40 \%$ of the time. In their second experiment, false recall of the critical lure was even higher (i.e., $55 \%$ ), while the false recognition rate was $76 \%$.

Our results are in line with those reported by Watson and colleagues (2005), who also failed to find a significant correlation between recall of critical lure words and a working memory task. However, contrary to these authors, we found that, even without warning, a negative relationship exists between executive simple span verbal working memory and false recognition of critical lures at testing.

\section{STUDY 2}

Watson and colleagues (2005) found an association between the o-span task and false recall in the DRM paradigm, but only after participants had been warned of the possibility of the DRM paradigm to elicit false recall, thereby putting increased demands on working memory leading to reduced encoding of distinctive information. In our study, no warnings were given and nevertheless a correlation was found between the backward digit span task and false recognition, in the DRM paradigm. There are two explanations for these discrepant findings. First, reliance on different working memory tests, simple span versus complex span, might account for the discrepancy. It could well be the case that different WMC indices (tapping different working memory loads) would have a differential influence on source monitoring. Second, we tested for false recognition after our participants had been given a free recall test. Thus, the recognition scores of our participants may be contaminated by prior free recall performance. To clarify these two possibilities, we conducted a second study in which three different working memory measures were included: forward digit span and backward digit span as simple span tasks and o-span as a complex span task. In this second study, it was further investigated whether different working memory indices contributed differentially to source monitoring judgements. In addition, participants were given a DRM recognition task, without prior recall. We hypothesised that, since participants were not given a warning during DRM recognition, we would find no association between o-span and false recognition. However, as in Study 1, we did expect to find a negative correlation between backward digit span and false recognition. 


\section{Method}

\section{Participants}

Sixty-five (16 men) psychology undergraduate students took part in this study. They received course credits in return for participation. Mean age of the participants was 18.88 years $(S D=1.13$; range: $17-22)$. Exclusion criteria were identical to Study 1.

\section{Procedure and materials}

The procedure used was similar to that in Study 1 with the exception that no free recall was obtained and that we included the o-span task. Participants were tested individually in a quiet laboratory room. After signing the informed consent form, participants underwent the DRM paradigm, the two digit span tasks, and the o-span task.

Deese/Roediger-McDermott paradigm. In this study, the 10 lists of the first study were extended with 6 lists to reduce the probability of ceiling effects. The 16 word lists were drawn from a Dutch normative study (Peters et al., 2006). As in Study 1, each list consisted of 15 words semantically related to a nonpresented critical lure word. The procedure of list presentation was similar to Study 1, but this time the recall phase after each list was omitted. Lists were presented one after another with a $2 \mathrm{~s}$ interlist interval. After the 16 word lists had been presented, digit span tasks and the o-span task were administered (order of working memory tasks was counterbalanced; see below). Participants were then given an oldnew recognition task consisting of 16 critical lures of the studied lists completely intermixed with 48 study words (the first, eighth, and tenth word of each studied list) and 32 unrelated lures taken from nonpresented lists. Only words unrelated to the words in the studied lists were used as unrelated lures. For each of these 96 words, participants had to indicate whether the word was old (i.e., had appeared on one of the 16 lists) or new.

Forward and backward digit span. The digit span tasks were the same as those used in Study 1.

Operation span task. The o-span task, as described by Engle, Cantor, and Carullo (1992) and Turner and Engle (1989), is a measure of complex working memory capacity. In this task, participants are presented with operation-word pairs (i.e., operation strings). In the present experiment the version of Engle et al. (1992) was used. The operation part is a mathematical equation which the participant has to read aloud. Next, he/she has to verify whether the proposed solution of the equation is correct or incorrect. The 
mathematical equation consists of 2 simple operations: a multiplication or division problem and an addition or subtraction problem. An example would be: $(8 / 4)+5=7$. Participants are not allowed to use pen and paper or to make the intermediate calculations aloud. When the participant has verified the equation, he/she has to read aloud the to-be-recalled word that stands behind the equation and press the spacebar as quickly as possible. Only words that did not appear in the DRM task were used in the o-span task. Following this, another word-equation item appears. The number of operation strings in a trial increased from two to five with tree trials at each set size. Set size varied pseudorandomly. There were 3 practice trials each containing two operation strings and 12 experimental trials. After the last operation in a trial, the participant saw a set of three question marks centred on the screen. Participants were then asked to write down the words, in correct order, that followed the operation strings. O-span score was calculated according to the partial-credit-unit weighted (PCU) procedure as described in Conway et al. (2005). When a participant had fewer then $85 \%$ of the equation items correct, his or her o-span data were excluded.

\section{Data analysis}

Analyses were similar to those carried out in Study 1. Alpha was set at .05 (two-tailed). Three DRM indices were derived: proportion recognition of old words, recognition of critical lure words, and recognition of unrelated lures.

\section{Results and discussion}

Table 3 shows the mean proportions of accurately recognised old words, falsely recognised critical lures, and unrelated lures. As can be seen, the data are well in line with the proportions found in Study 1. Thus, the hit rate for recognising studied words was .75 $(S D=.10)$, while the false alarm rate was practically identical to the hit rate $(M=.79, S D=.18)$. The mean proportion score for falsely recognising unrelated lures was .17 $(S D=.12)$.

Pearson correlations between the backward and forward digit span and the o-span task were all nonsignificant, all $r \mathrm{~s}<.15$, all $p \mathrm{~s}>.05$, two-tailed, showing that they measure different aspects of working memory. For the forward and backward digit span task a similar, although significant, correlation was found as in Study $1, r=.27, p=.03$. Pearson productmoment correlations were calculated between the three DRM indices, forward and backward digit span scores, and o-span scores. Replicating the findings of Study 1, no significant correlations were found between recognition of the studied words on the one, and the two digit span tasks and 
TABLE 3

Mean proportion scores (including $S D$ and range) for recognition of studied words, critical lure words, and unrelated words. Forward and backward digit span scores and operation span scores are given as mean overall scores

\begin{tabular}{lccc}
\hline Item type & Mean & $S D$ & Range \\
\hline Recognition & & & \\
Recognition studied words & .75 & .10 & .44 \\
Recognition critical lures & .79 & .18 & .88 \\
Recognition unrelated lures & .17 & .12 & .53 \\
& & & \\
Digit span & 5.50 & 1.02 & 4.00 \\
Forward digit span & 4.50 & .81 & 4.00 \\
Backward digit span & .79 & .09 & .41 \\
Operation span* & & & \\
\hline
\end{tabular}

*As indexed by partial-credit-unit weighted (PCU) score. See Conway, Kane, Bunting, Hambrick, Wilhelm, and Engle (2005).

o-span task, on the other hand: $r_{\text {forward }}=.02, p>.05$, two-tailed; $r_{\text {backward }}=$ $-.16, p>.05$, two-tailed; $r_{\mathrm{o} \text {-span }}=-.07, p>.05$, two-tailed. Neither were there significant correlations between recognition of unrelated lures, the two digit span parameters, and the o-span task (similar direction of relationship), all $r \mathrm{~s}<.15, p \mathrm{~s}>.05$. However, as in Study 1, false recognition of critical lures was significantly and negatively correlated with backward digit span, $r=-.49, p<.01$, two-tailed. For the forward digit span task and the o-span task, no significant correlations were found when related to the false recognition of critical lure scores, $r=-.17, p=.18$, and $r=-.01$, $p=.93$, respectively. Figure 1 shows the scatterplot of backward digit span scores and false recognition of critical lures. As can be seen, the significant correlation between these two variables is not explained by outliers, an impression that is confirmed by the Cook's distance $($ range $=.25) .^{2}$

As in Study 1, multiple linear regression analysis was carried out to determine the amount of variance in the false recognition of critical lures explained by forward and backward digit span scores and o-span performance. The results are shown in Table 4. When entering forward and backward digit span, and o-span (enter method) to explain variance in critical lure recognition, neither forward digit span nor o-span contributed significantly to the model. Only backward digit span was found to

\footnotetext{
${ }^{2}$ As in Study 1, corrected false recognition of critical lures was calculated $(M=.63$, $S D=.16$, range $=.75$ ) to control for possible ceiling effects in false recognition. In line with Study 1, and the described analyses in Study 2, when correlations were calculated between the corrected false recognition of critical lures and the working memory indices, only backward digit span significantly correlated to corrected false recognition, $r=-.50, p<.01$.
} 


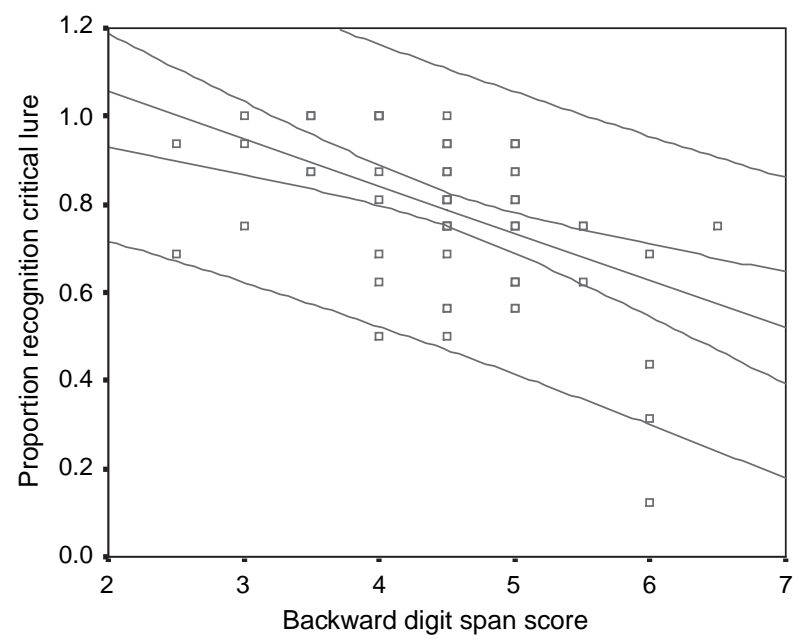

Figure 1. Scatter plot displaying the relationship between backward digit span score and false recognition of critical lure. The central line displays the regression line. The two outer lines display the prediction intervals of the regression line for single observations. The two lines most closely to the regression line display the prediction intervals of the mean predicted responses.

contribute significantly, with the amount of variance explained by this model being $23.8 \%\left(R^{2}=.238\right)$.

As was the case in Study 1, we found in Study 2 a negative correlation between backward digit span and false recognition of critical lure words. Replicating and extending the findings of Watson and colleagues (2005), we failed to find a link between the o-span task and false recognition. This could indicate that different working memory tasks (simple vs. complex WMC) may have a differential effect on source monitoring errors.

TABLE 4

Summary of regression analysis for variables predicting false recognition of critical lures $(N=65)$

\begin{tabular}{lcccc}
\hline Variable & $B$ & $S E B$ & $\beta$ & $t$ \\
\hline Recognition & & & & \\
Digit span forward & -.01 & .02 & -.04 & -.36 \\
Digit span backward & -.11 & .03 & -.48 & $-4.12^{*}$ \\
Operation span & .04 & .23 & .02 & .20 \\
\hline
\end{tabular}

$R^{2}=.238$.

$B=$ unstandardised regression coefficient; $S E B=$ standard error unstandardised regression coefficient; $\beta=$ standardised regression coefficient; $t=t$-value.

$* p<.01$. 


\section{GENERAL DISCUSSION}

In the current studies we employed several working memory tasks to test the idea that poor working memory capacity predicts susceptibility to false memories. In the first study, the working memory tasks differed with respect to the amount of executive functioning that they required, with the backward digit span task requiring more executive functions than the forward digit span task. In the second study, the tasks differed in terms of executive function involvement (i.e., backward vs. forward digit span tasks). Yet, they also differed in terms of complexity (i.e., the number of parallel processes they required), with the o-span task tapping more processes (verbal and arithmetic) than the simple digit span tasks. The results of the two studies converge on the conclusion that, under certain circumstances, one particular type of simple span working memory, namely backward digit span, is linked to false memory. Thus, our findings suggest that even in a homogeneous sample of undergraduates small variations in working memory are linked to individual differences in false memory proneness. Reduced working memory processing may undermine episodic encoding of the different word lists, thereby lacking the distinctive perceptual information needed to differentiate the semantically related critical lure words from presented words. As a consequence, source monitoring errors will occur.

In general, our results are well in line with those of Watson et al. (2005), but they also seem to differ with certain aspects of their work. In line with Watson et al., we were unable to detect a straightforward relationship between working memory capacity and false recall (Study 1). In Study 2, we extended the results of Watson et al. by failing to find a relation between o-span and false recognition in a standard DRM paradigm. However, unlike Watson et al., who found a relationship between poor working memory and false memory only when participants were given a warning, we did find that the executive index of simple span working memory task predicted false recognition in a standard DRM paradigm, even when no warning instruction was given.

A question that arises is whether the discrepancy in findings between the Watson et al. (2005) study and our studies can be attributed to the use of different working memory tasks. Put it in more general terms, do different working memory indices (depending on different loading demands) differentially contribute to source monitoring? Working memory can be seen as a multicomponent system that is responsible for active maintenance of information in the face of ongoing processing demands and/or distraction (e.g., Conway et al., 2005). Nonexecutive simple span tasks (i.e., tasks that only present to-be-recalled items; e.g., forward digit span) use a limited amount of resources and thus have a limited amount of loading demands; 
executive simple span tasks (i.e., tasks that present to-be-recalled information, but also require additional transformations; e.g., backward digit span) employ more resources (higher loading capacity); executive-attention working memory capacity tasks (e.g., operation span task) demand a substantial amount of resources with higher loading capacity (Conway et al., 2005; Gerton et al., 2004; Oberauer, Süß, Schulze, Wilhelm, \& Wittmann, 2000; Turner \& Engle, 1989). The current findings as well as those of others (Watson et al., 2005) suggest that when processing demands are high (as with warning instruction along with the DRM task in the Watson et al. study), complex working memory capacity will predict source monitoring failures. When one has poor complex WMC in a high processing demand environment, WMC is easily overloaded, leading to reduced encoding of distinctive features of the to be remembered information (e.g., semantically related words). When one has to retrieve this information, these distinctive features can not be used, leading to reliance on more general features such as semantic-relatedness, which in turn would result in source monitoring errors. On the other hand, when specific tasks do not require high processing demands (e.g., standard DRM procedures used in the present studies), simple span working memory will predict source monitoring failures. However, we do not know whether simple span working memory (nonexecutive and executive) is related to source monitoring failures under high processing demand circumstances (e.g., warning manipulation in the DRM paradigm). This issue warrants further research.

Several limitations of the current study deserve some comment. First, our finding that working memory is negatively related to false memories was most evident for the backward version of the digit span and the recognition modality of the DRM. Note that in homogeneous samples like the present ones, strongest effects are expected to occur for the most sensitive index of false memories, namely recognition of critical lures (e.g., Roediger \& McDermott, 1995; Stadler, Roediger, \& McDermott, 1999). In line with this, one has to be cautious about ceiling effects in the recognition task. Calculating corrected false recognition measure could help solving this problem. Also, the backward task is believed to be the purest measure of central executive working memory (e.g., Gerton et al., 2004). Meanwhile, the backward digit span is a subtask of the Wechsler Adult Intelligence Scale and therefore this variable overlaps with full-scale IQ. Thus, one could argue that our results reflect a link between false memory and low intelligence rather than poor working memory. However, recent research exploring the factor structure of the WAIS in a mixed patient sample and a neurological patient sample (Ryan \& Paolo, 2001; Ryan, Paolo, Miller, \& Morris, 1997) identified a distinct "working memory factor", which incorporated primarily the digit span task. It should be noted further that we tested first-year 
psychology undergraduate students and thus one may assume that the fullscale IQ did not vary much in this homogeneous sample.

Second, one could argue that the digit span tasks we used can be considered rather crude measures of working memory. However, given the frequent use of these tests in neuropsychological research and clinical practice (see, for example, Gerton et al., 2004; Iverson \& Tulsky, 2003; Lezak, Howieson, \& Loring, 2004), digit span tasks have become standard measures of working memory for which clear normative data are available.

The current findings as well as those of Watson et al. (2005) provide strong support for the idea that subtle variations in executive functions of the prefrontal areas contribute to the reconstructive aspects of our memory. Our findings are also well in line with previous work in our lab showing that mild executive dysfunctions in undergraduates reliably predict the extent to which they remember words never presented (Peters et al., in press). These findings are important because they might shed light on neuropsychological factors that make individuals susceptible to false memories. Similarly, they may help to explain why certain personality traits are intimately linked to false memories. A number of traits, notably dissociative tendencies and depression (or negative affectivity), seem to predispose to false memories (e.g., Candel, Merckelbach, \& Kuijpers, 2003; Eisen \& Lynn, 2001). The connection between these traits and false memories is, however, far from robust (Horselenberg et al., 2000). Perhaps, then, these traits serve as antecedents of false memories to the extent that they are accompanied by subtle disturbances in executive functions of the prefrontal areas. Indirect support for this line of reasoning comes from studies reporting a certain amount of overlap between poor working memory and dissociation (Giesbrecht, Merckelbach, Geraerts, \& Smeets, 2004). Clearly, the precise connection between dissociative tendencies, depression, and executive functions deserves further study.

Original manuscript received April 2005 Revised manuscript received December 2005 First published online 5 July 2006

\section{REFERENCES}

Alexander, K. W., Goodman, G. S., Schaaf, J. M., Edelstein, R. S., Quas, J. A., \& Shaver, P. R. (2002). The role of attachment and cognitive inhibition in children's memory and suggestibility for a stressful event. Journal of Experimental Child Psychology, 83, 262-290.

Baddeley, A. D. (1996). The fractionation of working memory. Proceedings of the National Academy of Sciences of the United States of America, 93, 13468-13472.

Baddeley, A. D., \& Hitch, G. (1974). Working memory. In G. A. Bower (Ed.), The psychology of learning and motivation (Vol. 8, pp. 47-89). Hillsdale, NJ: Lawrence Erlbaum Associates, Inc. 
Candel, I., Merckelbach, H., \& Kuijpers, M. (2003). Dissociative experiences are related to commissions in emotional memory. Behaviour Research and Therapy, 41, 719-725.

Conway, A. R. A., Kane, M. J., Bunting, M. F., Hambrick, D. Z., Wilhelm, O., \& Engle, R. W. (2005). Working memory span tasks: A methodological review and user's guide. Psychonomic Bulletin and Review, 12, 769-786.

Deese, J. (1959). On the prediction of occurrence of particular verbal intrusions in immediate recall. Journal of Experimental Psychology, 58, 17-22.

D'Esposito, M., \& Postle, B.R. (2002). The neural basis of working memory storage, rehearsal and control processes. In L. R. Squire \& D. L. Schacter (Eds.), Neuropsychology of memory (3rd ed., pp. 215-224). New York: Guilford Press.

Dodson, C. S., \& Schacter, D. L. (2002). The cognitive neuropsychology of false memories: Theory and data. In A. D. Baddeley, M. D. Kopelman, \& B. A. Wilson (Eds.), Handbook of memory disorders (pp. 343-362). Chichester, UK: Wiley.

Eisen, M. L., \& Lynn, S. J. (2001). Dissociation, memory, and suggestibility in adults and children. Applied Cognitive Psychology, 15, S49-S73.

Engle, R. W., Cantor, J., \& Carullo, J. J. (1992). Individual differences in working memory and comprehension: A test of four hypotheses. Journal of Experimental Psychology: Learning, Memory, and Cognition, 18, 972-992.

Gerton, B. K., Brown, T. T., Meyer-Lindenberg, A., Kohn, P., Holt, J. L., Olsen, R. K., \& Berman, K. F. (2004). Shared and distinct neurophysiological components of the digits forward and backward tasks as revealed by functional neuroimaging. Neuropsychologia, 42, 1781-1787.

Giesbrecht, T., Merckelbach, H., Geraerts, E., \& Smeets, E. (2004). Dissociation in undergraduate students: Disruptions in executive functioning. Journal of Nervous and Mental Disease, 192, 567-569.

Ginsburg, N., \& Karpiuk, P. (1994). Random number generation: Analysis of responses. Perceptual and Motor Skills, 79, 1059-1067.

Ginsburg, N., \& Karpiuk, P. (1995). Simulation of human performance on a random generation task. Perceptual and Motor Skills, 81, 1183-1186.

Gonsalves, B., \& Paller, K. A. (2002). Mistaken memories: Remembering events that never happened. The Neuroscientist, 8, 391-395.

Hedden, T., \& Park, D. C. (2003). Contributions of source and inhibitory mechanisms to agerelated retroactive interference in verbal working memory. Journal of Experimental Psychology: General, 132, 93-112.

Horselenberg, R., Merckelbach, H., Muris, P., Rassin, E., Sijsenaar, M., \& Spaan, V. (2000). Imagining fictitious childhood events: The role of individual differences in imagination inflation. Clinical Psychology and Psychotherapy, 7, 128-137.

Iverson, G. L., \& Tulsky, D. S. (2003). Detecting malingering on the WAIS-III unusual digit span performance patterns in the normal population and in clinical groups. Archives of Clinical Neuropsychology, 18, 1-9.

Johnson, M. K., Hashtroudi, S., \& Lindsay, D. S. (1993). Source monitoring. Psychological Bulletin, 114, 3-28.

Kane, M. J., \& Engle, R. W. (2002). The role of prefrontal cortex in working-memory capacity, executive attention, and general fluid intelligence: An individual differences perspective. Psychonomic Bulletin and Review, 9, 637-671.

Kopelman, M. D. (1999). Varieties of false memory. Cognitive Neuropsychology, 16, 197-214.

Kopelman, M. D. (2002). Disorders of memory. Brain, 125, 2152-2190.

Kroll, N. E. A., Knight, R. T., Metcalfe, J., Wolf, E. S., \& Tulving, E. (1996). Cohesion failure as a source of memory illusions. Journal of Memory and Language, 35, 176-196.

La Pointe, L. B., \& Engle, R. W. (1990). Simple and complex word spans as a measure of working memory capacity. Journal of Experimental Psychology: Learning, Memory, and Cognition, 16, 1118-1133. 
Lezak, M. D., Howieson, D. B., \& Loring, D. W. (2004). Neuropsychological assessment. Oxford, UK: Oxford University Press.

Lödvén, M. (2003). The episodic memory and inhibition accounts of age related increases in false memories: A consistency check. Journal of Memory and Language, 49, 268-283.

Marsh, E. J., Balota, D. A., \& Roediger, H. L., III. (2005). Learning facts from fiction: The effects of healthy aging and early stage dementia of the Alzheimer's type. Neuropsychology, 19, 115129.

McDermott, K. B. (1996). The persistence of false memories in list recall. Journal of Memory and Language, 35, 212-230.

McDermott, K. B., \& Watson, J. M. (2001). The rise and fall of false recall: The impact of presentation duration. Journal of Memory and Language, 45, 160-176.

Melo, B., Winocur, G., \& Moscovitch, M. (1999). False recall and false recognition: An examination of the effects of selective and combined lesions to the medial temporal lobe/ diencephalons and frontal lobe structures. Cognitive Neuropsychology, 16, 343-359.

Mitchell, K. J., Johnson, M. K., Raye, C. L., \& Greene, E. J. (2004). Prefrontal cortex activity associated with source monitoring in a working memory task. Journal of Cognitive Neuroscience, 16, 921-934.

Moscovitch, M. (2000). Theories of memory and consciousness. In E. Tulving \& F. I. M. Craik (Eds.), The Oxford handbook of memory (pp. 609-625). New York: Oxford University Press.

Oberauer, K., Süß, H. M., Schulze, R., Wilhelm, O., \& Wittmann, W. W. (2000). Working memory capacity: Facets of a cognitive ability construct. Personality and Individual Differences, 29, 1017-1045.

Parkin, A. J. (1997). The neuropsychology of false memory. Learning and Individual Differences, 9 , $341-357$.

Peters, M. J. V., Jelicic, M., Haas, N., \& Merckelbach, H. (in press). Mild executive dysfunctions in undergraduates are related to recollecting words never presented. International Journal of Neuroscience.

Peters, M. J. V., Jelicic, M., \& Merckelbach, H. (2006). Inducing false memories: A Dutch version of the Deese/Roediger-McDermott paradigm. Manuscript submitted for publication.

Reinitz, M. T., \& Hannigan, S. (2004). False memories for compound words: Role of working memory. Memory and Cognition, 32, 463-473.

Roediger, H. L., III., \& McDermott, K. B. (1995). Creating false memories: Remembering words not presented in lists. Journal of Experimental Psychology: Learning, Memory, and Cognition, $21,803-814$.

Ruffman, T., Rustin, C., Garnham, W., \& Parkin, A. J. (2001). Source monitoring and false memories in children: Relation to certainty and executive functioning. Journal of Experimental Child Psychology, 80, 95-111.

Ryan, J. J., \& Paolo, A. M. (2001). Exploratory factor analysis of the WAIS-III in a mixed patient sample. Archives of Clinical Neuropsychology, 16, 151-156.

Ryan, J. J., Paolo, A. M., Miller, D. A, \& Morris, J. (1997). Exploratory factor analysis of the Wechsler adult intelligence scale-revised in a sample of brain-damaged women. Archives of Clinical Neuropsychology, 12, 683-689.

Schacter, D. L. (1999). The seven sins of memory: Insights form psychology and cognitive neuroscience. The American Psychologist, 54, 182-203.

Schacter, D. L., \& Slotnick, S. D. (2004). The cognitive neuroscience of memory distortion. Neuron, 44, 149-160.

Stadler, M. A., Roediger, H. L., III., \& McDermott, K. B. (1999). Norms for word lists that create false memories. Memory and Cognition, 27, 494-500.

Stinissen, J., Willems, P., Coetsier, P., \& Hulsman, W. (1970). Handleiding bij de Nederlandstalige bewerking van de Wechsler Adult Intelligence Scale (WAIS) [Manual for the Dutch version of the WAIS]. Lisse, The Netherlands: Swets \& Zeitlinger. 
Turner, M. L., \& Engle, R. W. (1989). Is working memory capacity task dependent? Journal of Memory and Language, 28, 127-154.

Watson, J. M., Bunting, M. F., Poole, B. J., \& Conway, A. R. A. (2005). Individual differences in susceptibility to false memory in the Deese-Roediger-McDermott paradigm. Journal of Experimental Psychology: Learning, Memory, and Cognition, 31, 76-85.

Watson, J. M., McDermott, K. B., \& Balota, D. A. (2004). Attempting to avoid false memories in the Deese/Roediger-McDermott paradigm: Assessing the combined influence of practice and warnings in young and old adults. Memory and Cognition, 32, 135-141.

Wechsler, D. (1997). Administration and scoring manual for the Wechsler Adult Intelligence Scale (3rd ed.). San Antonio, TX: Psychological Corporation.

Williams, M. A., Moss, S. A., Bradshaw, J. L., \& Rinehart, N. J. (2002). Random number generation in autism. Journal of Autism and Developmental Disorders, 32, 43-47. 